Conscientious Objection in the Health Field in Spain. An iusophosophical perspective

\title{
La objeción de conciencia en el ámbito sanitario en España. Una perspectiva iusfilosófica
}

Juan Antonio Delgado de la Rosa

Doctorando en la Escuela Internacional de Doctorado

Universidad Rey Juan Carlos

pukopatuko@gmail.com

DOI: https://doi.org/10.15366/bp2019.22.012

Bajo Palabra. II Época. № 22. Pgs: 239-256

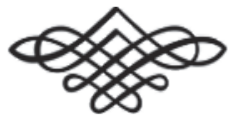


Recibido: 11/06/2019

Aprobado: 02/10/2019

\section{Resumen}

El problema de la objeción de conciencia en el ámbito sanitario no está cerrado, ni desde el punto de vista de la fenomenología social ni desde la óptica jurídica. Hay conflictos entre convicciones profundas del ser humano y los deberes jurídicos $y$, por otra parte, hay una creciente multiculturalidad de las diferentes sociedades. En esta perspectiva, surgen preguntas radicales (de raíz) que evidentemente son complejas, pero que a la vez tocan, como agua de rocío, lo más nuclear de la existencia, tanto de cada individuo como del conjunto de esa sociedad. Es fundamental el profundizar en la necesidad de regular jurídicamente dicha objeción de conciencia, en beneficio de un Estado de Derecho Democrático y Social donde no se vulnere o conculque ningún aspecto nuclear para la comprensión y aprehensión del ser humano y su inabarcable riqueza.

Palabras clave: Objeción de conciencia, filosofia del derecho, jurisprudencia, Constitución española, bioderecho, bioética.

\section{Abstract}

The problem of conscientious objection in the health field is not closed, neither from the point of view of social phenomenology nor from the legal point of view. There are conflicts between deep convictions of the human being and legal duties and, on the other hand, there is a growing multiculturality of different societies. In this perspective, radical questions arise (root) that are obviously complex, but at the same time touch, as dew water, the most nuclear of existence, both of each individual and the whole of that society. It is fundamental to deepen the need to legally regulate this objection of conscience, for the benefit of a Democratic and Social State of Law where no nuclear aspect is violated or violated for the comprehension and apprehension of the human being and his boundless wealth.
Keywords: Conscientious objection, philosophy of law, jurisprudence, Spanish Constitution, biolaw, bioethics 


\section{Introducción}

EN LA ÉPOCA ACTUAL SE DA UNA CIERTA CONTRADiCCión entre la tendencia a despersonalizar (cosificar) al ser humano, que vemos en la ciencia, en la filosofía analítica, en el pathos antimetafísico de la cultura actual y la creciente conciencia de los derechos del hombre. Por ejemplo, el ex jesuita, doctor en Filosofía y en Derecho, José María Díez-Alegría planteaba que para que la sociedad funcionara y el orden jurídico fuera efectivo tenía que tener vigencia una ética civil, es decir, una ética que sea reconocida por la sociedad y que sirva de soporte al orden jurídico. Por tanto, en una sociedad democrática, pluralista y secular, los presupuestos éticos del orden jurídico tienen que estar sostenidos por la conciencia del pueblo, por el convencimiento compartido del conjunto de la sociedad. Necesitamos el camino del diálogo civil para alcanzar acuerdos en la medida que la conciencia colectiva va madurando.

La propuesta es clara, se debe atender prevalentemente los aspectos ético-social y ético-jurídico de la realidad encuadrada en el ámbito filosófico-jurídico real y exigente. Esto deriva de la propia dignidad de la persona humana. Salta a la vista que las cosas suceden en gran parte en nuestro mundo exactamente al revés de cómo deberían suceder ética y jurídicamente. Por eso, la solución y aportación humanista en justicia, exigida por la filosofía del derecho está en lograr una orgánica y ponderada diversidad, dentro de una sustancial igualdad, es decir, dentro de una real y efectiva solidaridad.

\section{La objeción de conciencia desde una perspectiva generalista}

LA CONCIENCIA PODRÍAMOS ENTENDERLA, en cuanto lugar neurálgico donde se enraízan las actitudes fundamentales que van a configurar la propia intrahistoria e historia del ser humano, es la que nos va a proyectar hacia el ejercicio de nuestra actuación ${ }^{1}$. Aquí emergen las razones de conciencia. Pero ¿qué encierra este concepto? ${ }^{2}$.

\footnotetext{
Esta investigación forma parte del trabajo sobre la objeción de conciencia en el ámbito sanitario en España que el doctorando está realizando, dirigido por la profesora de la URJC Cristina Hermida del Llano, para presentarlo como tesis doctoral.

1 Dilthey, W., Teorías de las concepciones del mundo, Revista de Occidente, Madrid 1974. Nos plantea que la compresión y aprehensión de la realidad es un momento clave en la formación de la persona, El vivir y conectar vida y conciencia es un proceso artesanal que nos implica, complica y hace replicar.

2 Alarcos Martínez, F.J., Objeción de conciencia y sanidad, Comares, Granada 2011, p. 2.
} 
El hombre tiene estricto derecho a seguir el dictamen de su conciencia recta, es decir, de una conciencia que ha llegado con toda sinceridad, después de haber puesto con toda honradez los medios que estaban a su alcance para averiguar el verdadero sentido y ámbito de sus deberes. Para evitar ambigüedades de terminología, cuando se habla de recta conciencia, la palabra conciencia significa: el dictamen de conciencia (la conciencia en acto). Es el dictamen de la razón práctica el que se llama propiamente conciencia. Es este dictamen, esta norma concreta dictada por la razón práctica, la que se califica de recta (cuando es sincera, honesta, responsable y prudente dentro de la situación y de las posibilidades concretas del sujeto moral) o de torcida- (cuando es insincera, culpablemente errónea e imprudente en la concreta situación)- afirmamos que al hombre le compete, como uno de sus derechos fundamentales de persona, el derecho a obrar según su recta conciencia. La estructura esencial de la conciencia humana es ser falible en el orden de la verdad especulativa e infalible en el orden de la verdad práctica, si el hombre moralmente adulto procede honestamente con toda sinceridad toda conciencia recta es digna de un respeto absoluto ${ }^{3}$.

El derecho y la moral, por ser ciencias prácticas de la vida humana, ofrecen en su desarrollo una especial fuerza de evidencia para la determinación de ciertas bases fundamentales. Esto no puede ser desconocido por la filosofía especulativa que debe bucear en la realidad total, en las vivencias completas y profundamente humanas, enriquecidas por resonancias axiológicas, por corrientes vivenciales de tipo volitivo-emocional, en que el hombre alcanza un contacto intenso y fecundo con la realidad y en que el entendimiento puede lograr sus intuiciones más reales.

Hay autores muy interesantes, como Julián Marías ${ }^{4}$, Dolores Franco, José Luis López-Aranguren ${ }^{5}$ que también junto a Díez-Alegría, reivindicaron que el hombre tiene derechos y obligaciones ${ }^{6} \mathrm{y}$, por tanto, que el ser humano es constitutivamente moral, ya que tiene la posibilidad de realizar una conciencia de bien y mal

\footnotetext{
${ }^{3}$ Díez-Alegría, J.M., La Libertad Religiosa. Estudio Teológico, Filosófico, Jurídico e Histórico, Instituto Católico de Estudios Sociales, Barcelona 1965.

${ }^{4}$ Remitimos a la conferencia que la profesora Cristina Hermida pronunció el 17 de diciembre de 2018, en el Café Gijón sobre Dolores Franco. En esta misma conferencia, aludió al marido de Dolores Franco, el pensador Julián Marías, expresando una idea nuclear de la conferencia, la profesora Cristina Hermida explicó que para ambos: "El ser humano es tanto lo que va haciendo, por lo que va optando como lo que ha dejado de hacer en su vida”.

5 López Aranguren, J.L., Ética, Revista de Occidente, Madrid 1958, pp. 137, 241-244, 248-249. En estas páginas aparece la ética de Díez-Alegría expuesta por Aranguren. Estuvieron unidos realmente por preocupaciones intelectuales, que posteriormente reconocen mutuamente.

${ }^{6}$ Remitimos al interesante estudio que realiza en, Díez Alegría, J.Ma., "Condiciones para el proyecto de una Europa humana”, Razón y Fe 224, números 1113/1114 (julio-agosto), 1991, pp. 13-23.
} 
morales y un sentido de responsabilidad ${ }^{7}$ depurando la conciencia en el crisol de su propio examen ${ }^{8}$.

El hombre es esencialmente persona, constitutivamente, un ser moral, libre y responsable, donde la mediación, de la conciencia, es esencial a su propia vida moral. Por tanto, la conciencia humana busca esencialmente la verdad, la verdad en su totalidad, aunque parcialmente pueda alcanzar una verdad formalmente adecuada, es decir, una verdad que expresa sin error aquel aspecto de la realidad que se considera. La conciencia humana no es infalible en el orden de la verdad especulativa?

El hombre desde su realidad tiene derecho a seguir el dictamen de su conciencia recta adecuadamente verdadera, también tiene derecho a seguir el dictamen de su conciencia recta afectada accidentalmente de algún error invencible. El hombre también tiene derecho a ser dejado en libertad de acción y de opción entre lo honesto y lo inhonesto. El error, por tanto, no tiene derechos, en tanto que error, no puede ser nunca fuente de derechos. Pero no puede significar nunca, ni que el que sigue su recta conciencia invenciblemente errónea accidentalmente y sustancialmente verdadera no tenga derechos imprescriptibles e inalienables, pertenecientes al orden radical de los derechos del hombre, ni que el que obra inhonestamente no pueda tener nunca verdadero derecho a que su libertad sea respetada por los demás hombres y por los poderes sociales humanos ${ }^{10}$.

\footnotetext{
7 Díez Alegría, J.Ma., Éticas y moral cristiana, XVI Congreso de Teología (Evangelio e Iglesia). Evangelio y liberación. Septiembre, 1996: "Hay una cierta unidad en la apreciación de que hay que hacer el bien y evitar el mal. Pero, en cambio, hay una innegable pluralidad en cuanto a la determinación de los contenidos de la bondad y la maldad. La conciencia que cada uno tiene de lo bueno y de lo malo depende mucho de la historia cultural en que está inserto, así como de las relaciones interpersonales en que ha vivido, durante los ańos en que se va fraguando la personalidad de cada cual. De aquí que, debajo de las convicciones sobre lo bueno y lo malo, no hay un fundamento metafísico universal e inmutable, que haga idéntico el contenido de esas convicciones en todas las personas de buena voluntad...esta dialéctica de pluralismo y convergencia que hay en el reino de lo ético, que es el de la dignidad y verdadera libertad, está invitando a los seres humanos al diálogo de conciencias, hacia la búsqueda común de un programa moral...en la humanidad todos somos buscadores de la verdad práxica y nunca hemos llegado hasta el final...”, pp. 213-214.

${ }^{8}$ En el siglo XIII, el franciscano San Antonio de Padua recordaba la importancia de creer a la propia conciencia: Sermones dominicales et in solemnitatibus, I, Padua 1895, p. 292.

9 Díez-Alegría, J.Ma., La libertad religiosa. Estudio teológico, filosófico-jurídico e histórico, Instituto Católico de Estudios Sociales, Barcelona 1965: "El derecho a obrar según el dictamen recto de conciencia es una facultad propia de la persona, una pertenencia propia de la persona jurídicamente reconocida y protegida en un orden jurídico justo, fundado en el orden objetivo. Exactamente lo mismo que el derecho a la vida, a la dignidad y al honor son derechos subjetivos fundados en el orden objetivo. Todos los llamados derechos del hombre son los derechos del sujeto, que competen a la persona humana de manera universal, imprescriptible e inviolable, por estar radicados en las bases mismas de la estructura metafísica del hombre..." pp. 30-31.

${ }^{10}$ Díez-Alegría, J.Ma ., La libertad religiosa. Estudio teológico, filosófico-jurídico e histórico, Instituto Católico de Estudios Sociales, Barcelona 1965, 41-42. También remitimos a DíEz-Alegría, J.Ma.. "Coexistencia ideológica y libertad de las conciencias: el problema teológico y filosófico-jurídico de la libertad religiosa”, Sociedad Española de Filosofía jurídica y social. Derecho y paz. Actas del I Congreso de Filosofía del Derecho, Octubre 1964, Instituto de Estudios Jurídicos y Consejo Superior de Investigaciones Científicas, pp. 144-147.
} 
Con el paso del tiempo, la delimitación del concepto de conciencia ha sido implementado y coadyuvado por otras aportaciones como la definición del profesor de moral en la facultad de teología de Granada y director de la cátedra andaluza de bioética Alarcos Martínez que plantea que la conciencia: "Parece ser el yo captado en sus últimas dimensiones, el lugar donde el hombre se autoconoce y decide desde sí mismo. Sería, por tanto, una realidad unitaria, más aún el centro de unificación de la persona. Pero esta unidad no es un dato inmediato, sino el resultado de un proceso fatigoso de unificación. En ella confluye los mecanismos instintivos y los dinamismos psicológicos del inconsciente, con ella se relacionan los elementos de racionalidad y voluntariedad propios del ser humano. Esto da razón de la necesidad de una continua formación y autoformación de la conciencia, si no quiere acabar en manos de unas fuerzas de disgregación, que determinan la ruptura de la persona. El mismo proceso de la formación de la conciencia es una dinámica que no se puede separar del proceso más global de integración y maduración de la persona misma" ${ }^{11}$.

P. Ricoeur en su obra Sí mismo como otro, tratará en la Universidad de Roma «La Sapienza», en 1987 desarrollar la parte ética de su obra. Invitándonos a mirar en profundidad, la importancia de pensar el sí mismo en cuanto otro ya que pare éste la ipseidad del sí mismo implica la alteridad en un grado muy íntimo. Desde estas coordenadas Ricoeur plantea la alteridad ética del otro como un paso a una comunidad ética que estaría constituida por una suma de nosotros que posibilitaría la libertad auténtica de cada ego y de la comunidad misma ${ }^{12}$.

Realmente todas estas reflexiones nos marcan la importancia que se le ha venido dando en el pensamiento iusfilosófico ${ }^{13}$ a la temática sobre la objeción de conciencia "y las tendencias a hacer autónomas todas las esferas de la existencia. En el marco socio-sanitario y de la salud, uno de los bienes primarios más cotizados en nuestras sociedades, se detecta esto de una manera patente" ${ }^{14}$. Las personas aspiran a seguir creciendo y desarrollando su libertad personal y por tanto la objeción se encuentra enmarcada en una ética de máximos. Pero tanto la libertad como la objeción ¿son derechos absolutos? No lo son y por tanto deben tener restricciones a la hora de ponerlos en formato práctico. Por todo ello, creo necesario que haya un trasvase del tema jurídico en lo ético como tarea urgente y sobre todo medir bien los parámetros en relación a la gestión del poder y el liderazgo y empoderamiento

\footnotetext{
11 Alarcos Martínez, F.J., Objeción de conciencia y sanidad, Comares, Granada 2011, pp. 4-5.

12 Ricoeur, P., Si mismo como otro, Siglo XXI, Madrid 1996, p. XIV y siguientes.

13 Nota: No nos vamos a extender más en las diferentes doctrinas, pero sería útil retener por ejemplo de la obra de I. Kant la Crítica a la razón práctica o la Metafísica de las costumbres, donde se plantea que todo hombre tiene conciencia moral y se siente observado y sometido por un juez interior. Esta idea de conciencia como tribunal interno.

${ }^{14}$ Alarcos Martínes, F.J (Dir)., Objeción de conciencia y sanidad, Comares, Granada 2011, p. 12.
} 
de diferentes sectores sociales para que las convicciones que se van madurando en una sociedad armonicen con el establecimiento del poder institucional. Es el increíble juego de la resistencia y el acatamiento de las normas ya que toda decisión tiene consecuencias más directas o menos sobre otras personas ${ }^{15}$. Aquí emerge una parte fundamental de la objeción de conciencia.

\section{La objeción de conciencia en el ámbito sanitario}

Me gustaría comenzar este apartado con el planteamiento que tiene Victoria Camps sobre el concepto de excelencia en las profesiones sanitarias ${ }^{16}$, donde plantea que las profesiones médicas y enfermería, tratan y se interrelacionan con personas que se encuentran en situaciones únicas, extraordinarias, complejas. Cada persona por ello, podemos decir que es única e irrepetible. Es muy interesante, en este sentido, el planteamiento de la profesora Camps, ya que parte de una premisa de gran envergadura: "El nacimiento de la bioética responde a la necesidad de recuperar la unidad perdida entre las ciencias y las humanidades" ${ }^{17}$. Esta unidad, creo sinceramente que, ayudará a preguntar y preguntarse por la persona en su totalidad.

Continúa Victoria Camps en su exposición explicando que la virtud de la prudencia es un elemento que puede ayudar mucho a mejorar esta situación: "Ser prudente, en el sentido clásico, significa nada más y nada menos que saber aplicar la norma adecuadamente. De algún modo, cada caso a tratar es único. Por ello, la medicina o la enfermería son profesiones en las que es evidente que la aplicación automática de unas normas o unos protocolos no puede funcionar" ${ }^{18}$. Desde este enfoque entendemos que es difícil la aplicación de unas normas de forma automática, mecánica que funcionan como elementos aislados al margen de la propia vida. Por tanto, la excelencia alumbra a aquellos valores que obligan moralmente en conciencia.

Aquí el concepto de obligación moral nos ayudará a tomar decisiones prudentes y óptimas ¿Cómo? Entendiendo que el aspecto de la obligación moral es problema

\footnotetext{
${ }^{15}$ Alarcos Martínes, F.J (Dir)., Objeción de conciencia y sanidad, Comares, Granada 2011: "Si una persona decide por ejemplo abortar o poner fin a su vida mediante ayuda médica, esta no es una elección exclusivamente privada, sino que posee determinadas implicaciones públicas de terceros. Si elevamos a carácter absoluto lo decidido en privado, lo público, la parte que tiene que intervenir para que pueda realizar mi elección, se convierte entonces e u mero instrumento al servicio de mi privacidad...los otros son también sujetos morales que pueden alegar razones para no intervenir...”, p. 21.

16 Camps, V., "La excelencia en las profesiones sanitarias", Humanitas. Humanidades Médicas. Tema del mes on-line, 21 (2007), pp. 1-13.

17 IBID., 21 (2007), p. 4.

18 IBID., 21 (2007), p. 7.
} 
palpitante. Este problema interesa por igual a la filosofía moral en general y a la filosofía del derecho en particular ${ }^{19}$. El campo del Derecho está esencialmente trascendido y transitado por el ámbito de lo moral, porque sin el bien y la obligación moral, el valor y la obligación jurídica son radicalmente insubsistentes. El ámbito jurídico se refiere trascendentalmente a lo moral, por eso hay una vinculación con lazos estrechamente fortalecidos entre la juridicidad y la eticidad.

En realidad, la obligatoriedad moral es una virtualidad del objeto moral, inteligiblemente aprehendido en su esencial necesidad, es decir, como valor a priori sobre el sujeto racional. La obligatoriedad proyecta necesariamente su moralismo sobre cualquier comportamiento que se defina como moralmente obligatorio, porque es imposible que la obligatoriedad moral, en cuanto a tal, informe de hecho un contenido, empírico o ideal, volitivo o fáctico sin comunicarle al mismo tiempo la característica moral que constituye su esencia misma ${ }^{20}$. Hay que renunciar, por tanto, a todo intento de disociación de los aspectos subjetivos y objetivos del Derecho ${ }^{21}$ y, a la vez, por exigencias de una fenomenología jurídica realista, a toda reducción que elimine del plexo axiológico jurídico la referencia a lo moral.

Atendiendo a estas cuestiones y el inmenso espacio que se abre a la medicina para prevenir enfermedades; promocionar y mantener la salud; aliviar el dolor; curar enfermos; cuidar de los que no pueden ser curados; evitar muertes prematuras; velar por una muerte en paz y digna la objeción de conciencia sanitaria

19 Díez-Alegría, J.Ma ., "El fundamento ontológico de la obligación en Ignacio Martins y en Luis de Molina hasta 1592", Pensamiento 7 (1951): "La obligatoriedad aparece siempre a lo menos como una propiedad esencial, sino ya como uno de los aspectos de la esencia misma del bien moral, considerado en el ámbito de sus realizaciones sustanciales y necesarias. Es decir, que aquellos valores morales cuya ausencia es antimoral (valores morales necesarios desde el punto de vista del orden moral) precisamente en cuanto valores morales necesarios, son siempre obligatorios, sea cual sea el proceso por el que la especulación filosófica trata de explicar la realidad y las fuentes de su obligatoriedad", pp. 5-6.

${ }^{20}$ Kant, en su Crítica de la razón práctica, planteó que la obligatoriedad supone libertad. Todo acontecer empírico, aún psicológico y humano está bajo el dominio categorial y necesario de un estricto determinismo causal. Para ampliar información de esta formulación remitimos al manual que reúne de forma excepcional el estudio de diferentes autores de filosofía: Tejedor Campomanes, C., Historia de la Filosofía en su marco cultural, SM, Madrid 1986: "Una definición: principios prácticos son proposiciones que contienen una determinación universal de la voluntad... cuatro teoremas: Teorema I manifiesta todos los principios prácticos que suponen un objeto (materia) de la facultad apetitiva como motivo determinante de la facultad, son empíricos y no pueden proporcionar ley práctica alguna; Teorema II expresa que todos los principios prácticos materiales pertenecen, sin excepción, a la misma clase, y figuran bajo el principio universal del amor a sí mismo o de la felicidad propia; Teorema III explica que si un ser racional pretende pensar sus máximas como leyes prácticas universales, sólo puede pensarlas como principios que contienen el fundamento de la determinación de la voluntad en virtud de su forma; Teorema IV la autonomía de la voluntad es el único principio de todas las leyes morales y de sus deberes... la ley fundamental de la razón práctica pura en relación con el Teorema III nos hace reflexionar sobre la siguiente cita: obra de tal modo que la máxima de tu voluntad pueda valer siempre, simultáneamente, como principio universal... aquí está lo esencial de la Crítica de la razón práctica", pp. 289-290.

${ }^{21}$ Entiéndase Derecho objetivo en el sentido de comportamiento prescrito y Derecho subjetivo como la fuerza de obligar a un comportamiento determinado. 
cobra nuevos espacios que conllevan una reflexión sin prejuicios sin ideologizarla con falacias simples. Se trata de descubrir y aportar nueva luz a un tema tan complejo como es la objeción de conciencia en el ámbito sanitario, donde entra y subyace una antropología determinada, enmarcada en unas formas históricas e intrahistóricas, pero no desligada de la filosofía del derecho y sus fundamentos jurídicos.

En esta sociedad marcadamente plural escribir hoy sobre la objeción de conciencia, desde los parámetros académicos es fundamental, ya que la actuación de los agentes sociales que intervienen en ella, debe ser escuchadas, desde las claves fundamentales del imperativo categórico, para asegurarnos en el Estado de Derecho Democrático y Social. Por tanto, es obvio, que la clave relacional entre todos los agentes es necesaria y sana. Por un lado, nos damos cuenta que no podemos dejar a un lado del camino dialógico, las reivindicaciones de conciencia de los profesionales en su integridad moral, ni a las personas que son atenidas por ellos "ante procedimientos que les resultan éticamente conflictivos, sino poner en relación sus intereses, derechos y posibles daños con los de las personas a las que atienden" 22 .

Hay una máxima que expresaba Hanna Arendt y era que no es posible elegir a las personas con las que convivimos, coincidimos, cohabitamos en este mundo ${ }^{23}$. Todos conformamos este mundo, y en el ámbito sanitario, se encuentra cada agente interviniente con sus circunstancias, tanto médico, personal sanitario, usuarios y pacientes, jueces. Por todo ello, es importante enmarcar en la medida de lo posible la objeción de conciencia en el marco de nuestra convivencia, tanto a nivel jurídico como sanitario. Entendiendo que quizás sea complejo prever todos los casos posibles de objeción de conciencia, y esto nos sitúa, en una objeción de conciencia dinámica, pero sin riesgo a entender, que desde ese dinamismo no haya que tener en cuenta el ámbito del derecho. No entiendo aquí si desde estas coordenadas se pueda aludir a una hiperjuridificación, e incluso si fuera necesario en algún momento, deberíamos apoyar dicha posibilidad, sin detrimento de nuestra privacidad.

\footnotetext{
22 Triviño Caballero, R., El peso de la conciencia. La objeción en el ejercicio de las profesiones sanitarias, CSIC/ Plaza y Valdés, Madrid/México 2014, p. 18.

23 Arendt, H., Eichmann en Jerusalén. Un estudio sobre la banalidad del mal, Lumen, Barcelona 2003 (la traducción es de Carlos Ribalta): "La jurisprudencia de los países civilizados quizá de ninguna otra nota se haya enorgullecido tanto como de la consistente en tener en cuenta el llamado factor subjetivo. Cuando dicho ánimo no concurre, cuando, por las razones que sea, incluso las de la locura moral, el sujeto activo no puede distinguir debidamente entre el bien y el mal, consideramos que no puede haber delito...el mundo dela política en nada se asemeja a los parvularios; en materia política, la obediencia y el apoyo son una misma cosa...nosotros consideramos que nadie, es decir, ningún miembro de la raza humana, tiene el derecho a decidir quién puede y quién no puede habitar el mundo...”, pp. 165-166.
} 
Un elemento central en lo que ataña a la objeción de conciencia en el ámbito sanitario, sobre todo en la parte que concierne a la filosofía del derecho, son los actos de dignidad moral cuando las convicciones están arraigadas y están mantenidas en el tiempo ${ }^{24}$. Aquí hay una clave fundamental. El concepto tiempo, que vincula estas acciones morales serias y sinceras al hecho de mantenerlas y que permanezcan tiempo. Esta vivencia constituye un factor, a mi modo de ver, determinante, para el Derecho y concretamente para el iusfilósofo. No se trata solamente del sucesivo paso de los días. Es la conjugación del valor ético en la intrahistoria singular en consonancia con el Derecho. Dicho de otro modo, si siguiéramos las ideas fundamentales de Heidegger en ser y tiempo, donde quería mostrar que el tiempo es el horizonte trascendental de la pregunta por el ser: mostrar que el tiempo pertenece al sentido del ser. Sin entrar en más dialéctica en el estudio de la obra Ser y tiempo, podemos situarnos desde estas coordenadas en la importancia del tiempo en la vida del dasein, donde inexorablemente lo constituye de suyo. Ciertamente, una ley no transforma la conciencia, por eso, se tiene que dar este trípode con absoluta calidad, me refiero a lo que ut supra comentaba, sobre encajar en la ética, la propia historia en relación al tiempo y al propio ser y su confluencia en el Derecho positivo. Esto garantizaría libertad, seguridad. Y lo más importante, se mantendría un equilibrio entre las cuestiones fundamentales que el ser humano tienen arraigada en su interior y el propio cumplimiento de la legalidad.

Como vemos, la conciencia tiene un papel fundamental, dentro de un estado de Derecho Democrático y Social, donde sería necesario mantener un equilibrio entre la libertad de conciencia y el derecho a objetar, teniendo en cuenta el marco legislativo dentro de este estado de derecho. Evidentemente, aquí nos surgen preguntas tales como: ¿El Estado de Derecho no debe bloquear la libertad de conciencia y el derecho a objetar, cuando una obligación legal choca contra ella? ¿Esto valdría para plantearse un cambio normativo? Habría que seguir profundizando en estas preguntas, donde entra en juego los conceptos de mayoría y minoría ${ }^{25}$. Es muy interesante la reflexión de Diego Gracia, ya que de fondo está una crítica al iusna-

${ }^{24}$ Triviño Caballero, R., El peso de la conciencia. La objeción en el ejercicio de las profesiones sanitarias, CSIC/ Plaza y Valdés, Madrid/México 2014, p. 306: "Hay un amplio acuerdo en que los asuntos relacionados con la conciencia implican la activación de las convicciones que resultan esenciales para el individuo, aquellas cuya vulneración implicaría la pérdida de la propia integridad moral".

25 Gracia, D., "Objeción de conciencia: las lecciones de un debate", Revista de Calidad Asistencial 26 (3), 2011: "En las democracias, las leyes se aprueban por mayoría en las cámaras representativas. Se supone, por ello, que tales leyes expresan los valores morales, no de todos, pero sí de la mayor parte de los ciudadanos, razón por la cual estos han de considerar moralmente correcto lo que estipula la ley. Pero también es obvio que una minoría no lo verá así. Pues bien, las sociedades democráticas han establecido un procedimiento de respeto a tales personas. Ese procedimiento es la objeción de conciencia, que permite a un ciudadano no intervenir en algo que tiene por moralmente incorrecto, por más que se halle aprobado o incluso exigido por la ley. La objeción es una excepción legal al cumplimiento de la ley. Caso de que el legislador o los tribunales de justicia consideraren 
tiualismo estricto ${ }^{26}$. Aquí tengo que decir que estoy de acuerdo con él. No pueden negarse los principios como son el mutuo respeto, una atenta sensibilidad para todos los valores que dan sentido y nobleza a la vida humana y un común afán de construir un mundo más libre, más solidario y más justo. Hay que tener una clara visión de los principios fundamentales del orden filosófico-jurídico, para poder avanzar en el desarrollo de la objeción de conciencia sin que prevalezca la negación de ninguno derecho fundamental.

La ley moral exige la búsqueda a fondo de la dimensión liberadora ${ }^{27}$, que siempre reconoce el amor, el respeto, la promoción de la persona, para que ésta no pueda ser ni mediatizada ni aniquilada ${ }^{28}$. Por tanto, ¿Es necesario, profundizar en el concepto de la ley moral, de su estructura gnoseológica y normativa?

inapropiada la objeción en un caso concreto, el objetor dejará de ser tal para convertirse en insumiso. Que es lo que fueron todos los que se opusieron a cualquier ley en las sociedades predemocráticas o no democráticas. Los primeros cristianos que se negaron a adorar al emperador no fueron objetores, fueron insumisos, que es cosa distinta. Dentro de las sociedades democráticas, la objeción de conciencia es también un fenómeno reciente. Aparece como tal figura con posterioridad a la segunda guerra mundial. Fue con ocasión de esta contienda cuando surgió el conflicto en Estados Unidos, al negarse ciertos grupos del llamado protestantismo radical a empuñar las armas e ir a la guerra. Ahí comenzó el proceso de reflexión que acabaría por dotar de contenido a la objeción de conciencia. Ni que decir tiene que el ámbito al que se aplicó fue el militar. Dado que se trata del excepcional cumplimiento de una norma legítimamente promulgada, es claro que la objeción de conciencia tiene siempre carácter excepcional; es una excepción a la regla, que no puede ser otra que el cumplimiento de la ley. La excepción se hace con el objeto de respetar los valores de las minorías. De ahí que resulten extrañas y atípicas dos figuras cada vez más frecuentes. Una es querer convertir la objeción de conciencia no en excepción, sino en regla, y además absoluta y sin excepciones. Y otra, que se acojan a ella colectivos enteros de población, con lo que algo aplicable a minorías adquiere un uso mayoritario. Cuando esto último sucede, algo falla, pues si la mayoría está en contra de una norma, lo lógico es que esta se sustituya por otra que diga lo propugnado por los objetores. Cuando eso no sucede, hay que sospechar que la objeción no es auténtica, es decir, que se objeta por motivos que no son morales o de conciencia", pp. 143-145.

26 Rivaya, B., "La filosofía jurídica española (1936-1975)", en: Aa.Vv., Franquismus und Salazarismus: Legitimation durch Diktatur?, Herausgegeben von Dieter Simon, Berlín 2008: "Destacando íntegramente también la oposición al uso ideológico del Derecho Natural, va a ser José María Díez-Alegría, que precisamente por su condición de sacerdote evidenciaba cierto descontento eclesial con el uso que se venía haciendo del Derecho Natural en Espańa. Que Díez-Alegría, como Ruiz-Giménez, seguía siendo un iusnaturalista cristiano, resulta obvio, pero ahora utilizaba esa doctrina contra el franquismo: el pecado de Israel había sido querer aunar la religión con la injusticia y el atropello al prójimo y ejemplificaba ese pecado con el caso de la propiedad privada en España (Véase el artículo de Díez-Alegría Opción del bien y tolerancia intersubjetiva (1960) y su libro Actitudes cristianas ante los problemas sociales (1963)", pp. 286-287. Anteriormente se había referido este autor a la misma cuestión: Rivaya, B., "La filosofía del Derecho como concepto formal (Sobre la filosofía jurídica española de los años sesenta)": Boletín de la Facultad de Derecho 13 (1998) p. 23: “... Díez-Alegría seguía defendiendo las tesis clásicas del iusnaturalismo, es algo que resulta obvio al ver que identificaba el Derecho Natural con el recto orden, con el orden de la Providencia. En este punto su discurso no sería distinto del oficial, pero sí en aquel otro en que criticaba al franquismo por vulnerar ese orden natural que pretendía defender..." y remitía a las obras Díez-Alegría, J.M., Actitudes cristianas ante los problemas sociales, Barcelona, Estela 1963, pp. 48, 53, 61; y Díez-Alegría, J.M., "Opción del bien y tolerancia intersubjetiva": Anuario de Filosofía del Derecho VIII (1960) pp. 19-20.

27 Díez-Alegría, J.M., Aspectos actuales del problema de la ley moral natural, Aa.Vv. Homenaje a Xavier Zubiri, tomo I Moneda y crédito, Madrid 1970, pp. 456-457.

28 Ibíd., p. 458. 


\section{Conclusiones en el camino de la reflexión}

\section{Primera conclusión: ¿Bioderecho y bioteología?}

Es fundamental seguir profundizando en esta nueva rama jurídica que es el bioderecho, caracterizada por su atención al respeto y protección de la vida humana, desde la concepción hasta su final. Tendríamos que ir caminando a responder a la pregunta de ¿qué papel puede tener el bioderecho en nuestras sociedades? En esta pregunta está en juego el futuro del derecho mismo.

Quizás pase por plantearse también, en esta línea de pensamiento, una bioteología. La reflexión podría estar enmarcada en el debate, sobre si es en el mismo derecho natural, donde se puede postular la exigencia de una sociedad civil y una estructura jurídica positiva en virtud de exigencias radicales de la estructura metafísica de la persona humana, que es esencialmente social. El derecho (a secas) tiene realmente una validez normativa, no dependiendo de la contingente actitud de cada particular libertad. La bioteología, podría plantear si hay un orden natural que es vulnerado por razones de una mayoría frente a la minoridad. La Filosofía del Derecho debe tener conciencia que el último resolutivo de sus construcciones no le es inmanente, porque, en la jerarquía de los saberes humanos, aún naturales, unas disciplinas se abren sobre otras, hasta llegar al conocimiento de las últimas razones, que en este planteamiento bioteológico sólo se alumbran in luce dei. Podemos decir entonces que, desde las claves del Derecho Civil y su relación con la Ética, proyectará de forma inequívoca a la dimensión de Justicia.

Segunda conclusión: La importancia de las direcciones de valor

Los principios éticos de la ley moral tienen prevalentemente el carácter de direcciones de valor en un campo de valores de contenido material. Son abiertos a la evolución de los condicionamientos históricos, sociales y antropológicos, pero, a la vez, tienen la potencia de una dirección de valor, que tienen que ser, de alguna manera, traducidos en proposiciones, en normas concretas de conducta, que realicen concretamente en la vida los valores indicados por los principios

Las proposiciones representan un esfuerzo del espíritu humano, de la conciencia moral, para integrar y aplicar los principios éticos a la realidad concreta humana, esencialmente histórica y social, dando un contenido vivo en la historia y en la convivencia humana La cognoscibilidad de tales proposiciones éticas de conducta no es independiente de ciertas opciones de conciencia ya que representan una res- 
puesta a una llamada que viene de la realidad, del sentido real de la existencia, a la vez que una proyección de la luz interior, de la sabiduría moral de los principios.

Por tanto, cada vez es más necesario reflexionar en profundidad sobre los principios, para iniciar un proceso de búsqueda e iluminación, capaz de llegar a opciones que no sean puramente arbitrarias, que mantengan la dignidad que es propia de la conciencia.

El hombre, la persona humana, es un ser constitutivamente moral y sus acciones, por tanto, pueden tener una ineludible dimensión ética. Para ello, la ley moral, la norma humanamente cognoscible del bien y del mal, nos da orientaciones, sobre qué actos y en qué circunstancias son buenas o malas ${ }^{29}$.

Entendiendo la concepción de la ley moral como conjunto de principios, de orientaciones, de direcciones de valor y no como código de proposiciones, confiere a la conciencia moral de la persona el papel que le corresponde, porque sobre las indicaciones que vienen de los principios morales y delante la problemática complejidad de las situaciones, la conciencia personal busca un camino de salida, que muchas veces no podrá ser satisfactorio del todo, pero que en todo caso mirará de adecuarse a todas las exigencias axiológicas que se plantean en cada caso.

\section{Tercera conclusión: La educación de la bioética y del bioderecho}

Todas las cuestiones de bioética, bioderecho y bioteología deberían formar parte de un plan de estudios tanto para alumnos de $4^{\circ}$ de la ESO como de Bachillerato y por supuesto de las diferentes Universidades. Ya que estas realidades forman parte de la vida. Es compromiso inexorable del educador, del maestro trabajar por transmitir conocimientos y reflexiones en torno a problemas tan complejos No solamente acercar cierta literatura al respecto sino entrar en reflexionar en la clave iusfilosófica con respecto a estas cuestiones que a lo largo del trabajo de investigación hemos tratado de repensar.

Fundamental desde esta clave educativa exponer los retos que tenemos como ciudadanos y como sociedad con preguntas de hondo calado: ¿Qué valor tiene la

\footnotetext{
${ }_{29}$ La dignidad de la persona humana, la solidaridad interpersonal y social, el interés por el bien común, el no hagas al próximo lo que no te gusta a ti del rabino Hillel, el todo lo que queréis que los demás os hagan a vosotros hacedlo vosotros a ellos de Jesucristo, el tomar la humanidad, en ti mismo y en los demás siempre como fin, nunca como medio de Inmanuel Kant, la igualdad, libertad, fraternidad de la revolución francesa, el imperativo categórico de tirar por tierra todas las relaciones en que el hombre es esencia degradada de Karl Marx, todo esto son principios básicos que, de alguna manera, trascienden un puro relativismo cultural e histórico.
} 
dignidad de la persona? ¿Se puede hacer objeción de conciencia ante los Derechos Humanos? ¿Qué papel tiene en todo esto el Estado? ¿Cómo planificar una formación y educación pertinente para estos nuevos retos? ¿Cómo empoderarnos en el conocimiento y adhesión a los Derechos Humanos? Todo ello ayudará a abrir nuevos caminos desde el absoluto rigor jurídico y filosófico, para hacer un mundo más habitable. 


\section{Referencias Bibliográficas}

AA. VV., Constitución y derechos fundamentales, Centro de Estudios Políticos y Constitucionales, Madrid 2004.

Aa.Vv., Franquismus und Salazarismus: Legitimation durch Diktatur?, Herausgegeben von Dieter Simon, Berlín 2008.

Alarcos Martínez, F.J. (Dir.), Objeción de conciencia y sanidad, Comares, Granada 2011.

Arendt, H., Eichmann en Jerusalén, Lumen, Barcelona 2001.

Camps, V., Una vida de calidad, Ares y Mares, Barcelona 2000.

Camps, V., La voluntad de vivir, Ariel, Barcelona 2005.

Cortina, A., Ciudadanos del mundo. Hacia una teoría de la ciudadanía, Alianza editorial, Madrid 2005.

Courtis, C., Los derechos sociales como derechos exigibles, Trotta, Madrid 2002.

De Lora, P., y Gascón, M., Bioética. Principios, desafios, debates, Alianza editorial, Madrid 2009.

DíAz, E., La sociedad entre el Derecho y la Justicia, Salvat, Barcelona 1982.

Díez-Alegría, J.M., Ética, Derecho e Historia. El tema iusnaturalista en la problemática contemporánea, Sapientia, Madrid 1953.

Dilthey, W., Teorías de las concepciones del mundo, Revista de Occidente, Madrid 1974.

Dworkin, R., El dominio de la vida. Una discusión acerca del aborto, la eutanasia y la libertad individual, Ariel, Barcelona 1994.

Escobar Roca, G., La objeción de conciencia en la Constitución Española, Centro de Estudios Constitucionales, Madrid 1993.

Fernández-Coronado GonzÁlez (Directora)., El derecho de la libertad de conciencia en el marco de la Unión Europea: pluralismo y minorias, COLEX, Madrid 2002.

Flores, F., La objeción de conciencia en el derecho penal, Comares, Granada 2001. Gracia, D., Fundamentos de bioética, Triacastela, Madrid 2008. 
Heidegger, M., Sein und Zeit, Tübingen: Niemeyer, 19. Auflage 2006.

Heidegger, M., Naturaleza, Historia, Estado (edición y tra.ducción de Jesús Adrián escudero), Trotta, Madrid 2018.

Hermida del Llano, C., Los derechos fundamentales en la Unión Europea, Antropos, Barcelona 2005.

Hermida del Llano, C., La mutilación genital femenina. El declive de los mitos de legitimación, Tirant Lo Blanch, Valencia 2017.

Husserl, E., La filosofía como ciencia estricta, Nova, Buenos Aires 1984.

Junquera de Estéfani, R (dir.)., Bioética y bioderecho. Reflexiones jurídicas ante los retos bioéticos, Comares, Granada 2008.

Moreno Antón, M (coord.)., Sociedad, derecho y factor religioso. Estudios en honor del profesor Isidoro Martín Sánchez, Comares, Granada 2017.

Moro, T., De optimo reipublicae statudeque nova insula Utopía (original 1516), Sarpe 1984.

Navarro-Valls, R., y Martínez Torrón, J., Las objeciones de conciencia en el derecho español y comparado, McGraw-Hill, Madrid 1997.

Navarro-Valls, R., y Martínez Torrón, J., Conflictos entre conciencia y ley, Iustel, Madrid 2012.

Nussbaum, M.C., La fragilidad del bien, ed. Antonio Machado, Madrid 1995.

Ollero Tassara, A., Democracia y convicciones en una sociedad plural, Cuadernos del Instituto Martín de Azpilcueta, Navarra 2001.

Ollero Tassara, A., García Amado, J.A., Hermida del Llano., Derecho y moral: una relación desnaturalizada, Fundación Coloquio Jurídico Europeo, Madrid 2012.

Radbruch, G., Introducción a la filosofía del derecho, Fondo De Cultura Enconómica, Madrid 2002.

Radbruch, G., Arbitrariedad legal y derecho supralegal, Abeledo-Perrot, Buenos Aires 1962.

Rodríguez García, J.A., Derecho Eclesiástico del Estado, Tecnos, Madrid 2015.

Siera Mucientes, S., La objeción de conciencia sanitaria, Universidad de Comillas, Dykinson 2000. 
Singer, P., Repensar la vida y la muerte. El derrumbe de nuestra ética tradicional, Paidós, Barcelona 1997.

Triviño Caballero, R., El peso de la conciencia. La objeción en el ejercicio de las profesiones sanitarias, CSIC-Plaza y Valdés, Madrid-México 2014.

DOI: https://doi.org/10.15366/bp2019.22.012

Bajo Palabra. II Época. № 22. Pgs: 239-256 
